\title{
Does gliding when pregnant select for larger females?
}

\author{
H. B. Fokidis ${ }^{1,2} \&$ T. S. Risch ${ }^{1,2}$ \\ 1 Department of Biological Sciences, Arkansas State University, State University, AR, USA \\ 2 Savannah River Ecology Laboratory, Aiken, SC, USA
}

\section{Keywords}

body size; flying squirrel; gliding; sexual size dimorphism; wing loading.

\author{
Correspondence \\ H. Bobby Fokidis. Current address: School \\ of Life Sciences, Arizona State University, \\ PO Box 874601, Tempe, AR 85287-4601, \\ USA. \\ Email: Bobby.Fokidis@asu.edu \\ Editor: Virginia Hayssen \\ Received 4 October 2007; revised \\ 4 February 2008; accepted 18 February 2008 \\ doi:10.1111/j.1469-7998.2008.00433.x
}

\begin{abstract}
For terrestrial vertebrates, gliding imposes unique constraints on the interaction of body mass and structural size, particularly with reference to minimizing wing loading. Females of gliding animals experience increases in wing loading during pregnancy or gravidity, and selection may favour increased structural size to compensate for the added mass. We tested whether pregnant southern flying squirrels Glaucomys volans had similar wing loading as males, and whether females with lower wing loading bore heavier litters, than those with greater wing loading. Males had greater wing loading than females, regardless of the latter's reproductive state (males: $38.4 \pm 3.62 \mathrm{~N} \mathrm{~m}^{-2}$, pregnant females: $30.7 \pm 4.21 \mathrm{~N} \mathrm{~m}^{-2}$ and nonpregnant females: $26.8 \pm 5.13 \mathrm{~N} \mathrm{~m}^{-2}$ ). The slope of the linear relationship between planar surface area and body mass was similar between pregnant females and males, however $(F=0.383, P=0.322)$. Thus female flying squirrels may optimize their litter mass to minimize wing loading during pregnancy. Contrary to our prediction, females with greater wing loading had heavier litters than those with lower wing loading, which suggests reproductive output may be influenced by other ecological factors.
\end{abstract}

\section{Introduction}

Sexual size dimorphism (SSD) is attributed to differential selection acting separately, but concurrently on each sex (Andersson, 1994). Intersexual divergence in body size may be associated with female fecundity (Darwin, 1874; Howard et al., 1998; Reeve \& Fairburn, 1999), ecological niche separation (Slatkin, 1984; Shine, 1989; Temeles et al., 2000), sexual selection (Darwin, 1874; Webster, 1997) or differences in survival (Yoccoz \& Mesnager, 1998; SchulteHostedde, Millar \& Gibbs, 2002). Male-biased SSD is usually explained in the context of sexual selection acting on male body size during mate competition; however, selection could act to decrease female body size (Loison et al., 1999; Karubian \& Swaddle, 2001).

Hypotheses concerning the evolution of female-biased SSD vary and include: selection for smaller males (Ralls, 1976), female dominance (Kruuk, 1972), increased female fecundity (Howard et al., 1998; Schulte-Hostedde, Millar \& Gibbs, 2004), intersexual differences in survival (Yoccoz \& Mesnager, 1998) and enhanced mobility of pregnant or gravid females (Myers, 1978; Shine, 1988; Hayssen \& Kunz, 1996). The latter hypothesis may be particularly relevant for organisms where body size are major determinants of locomotor efficiency, such as in flying, gliding and swimming species (McGuire \& Dudley, 2005). Increases in body mass with reproduction can potentially interfere with selection for lighter or more aerodynamic body forms, which generally increases efficiency of locomotion (Shine, 1988).
In numerous studies, potential constraints on reproduction may have resulted from shifts towards novel locomotory modes (Hayssen \& Kunz, 1996; Davenport, 2003; McGuire \& Dudley, 2005; Fokidis \& Risch, 2008). Evidence for a reproductive constraint come from studies that have assessed locomotor impairment during gravidity in snakes (Shine, 1988), lizards (Olsson, Shine \& Bak-Olsson, 2000; Shine, 2003), raptors (Mueller \& Meyer, 1985) and bats (Hayssen \& Kunz, 1996). In flying species, increased body mass means an individual must generate more lift to overcome gravity (Hayssen \& Kunz, 1996; Guillemette \& Ouellet, 2005), and thus added mass during reproduction may be particularly important in these species. Indeed, this 'wing loading hypothesis' may explain adaptations in birds, such as sequential ovulation and oviparity that can result from the need to minimize mass associated with reproduction (Blackburn \& Evans, 1986).

Most mammals exhibit male-biased SSD, however Ralls (1976) compiled data on mammals exhibiting female-biased SSD and suggested that, although less common, femalebiased SSD is widespread in mammals (documented in c. 178 species from 13 orders). Ralls (1976) reasoned that female-biased SSD likely resulted from a variety of ecological factors that are not necessarily mutually exclusive, as opposed to direct sexual selection favouring large females. In mammals, the wing loading hypothesis has been applied to some bat species, where litter size and mass increase with the degree of female-biased SSD in forearm length and hence wing area (Myers, 1978). The mass gained during pregnancy increases wing loading. Thus, when females are 
larger than males they have an enlarged planar surface area of the airfoil, so that the lift to drag ratio is increased and the effects of this added mass are minimized (Hayssen \& Kunz, 1996). Although, these ideas were developed initially for bats, recent work has suggested similar constraints of pregnancy on species that engage in gliding locomotion. In the flying lizard Draco melanopogon, selection for the locomotor ability of egg-burdened females may have been responsible for the larger size of females compared with males, which is a pattern not observed in most agamid lizards (Shine et al., 1998). Several species of mammalian gliders exhibit female-biased SSD including; southern flying squirrels Glaucomys volans (Madden, 1974; Robins, Scheibe \& Laves, 2000; Fokidis, 2004; Fokidis, Risch \& Glenn, 2007), and red giant flying squirrels Petaurista petaurista (Lee, Lin \& Progulske, 1993; Lee, 1998). Gliding mammals are known to have longer gestation periods, slower development and generally larger offspring when compared with similarly size non-gliding mammals (Stapp, 1992; Holmes \& Austad, 1994; Fokidis \& Risch, 2008). These observations suggest that wing loading may be an important factor during reproduction.

To test the hypothesis that wing loading influences female reproductive output, we used morphological and reproductive data collected from southern flying squirrels, a species that exhibits female-biased SSD (Fokidis, 2004; Fokidis et al., 2007). Female G. volans typically produce two litters a year (litter size varies from 1 to 5), with smaller litter sizes in the spring than in late summer-early fall (Risch, 1999). Female $G$. volans are reproductively precocious and thus may be under selection for early breeding, before femalebiased SSD becomes conspicuous (Fokidis et al., 2007). Adult non-reproductive females can be up to $13 \%$ heavier than males, and litter size increases with female breeding experience (Fokidis et al., 2007).

We tested three predictions concerning the relationship of wing loading to reproduction: (1) when pregnant, female wing loading would be similar to that of males; whereas non-pregnant females would have lower wing loading than males; (2) females with lower wing loadings would bear heavier litters; (3) females breeding for the first time would bear proportionally lighter litters than at subsequent reproductive attempts, but wing loading values not differ.

\section{Methods}

\section{Field data collection}

Our study was conducted on a population of $G$. volans at the US Department of Energy's Savannah River Site, near Aiken, SC. The habitat on the study can be characterized as a mixture of upland hardwood forests and managed pine stands (Brady, Risch \& Dobson, 2000; Fokidis \& Risch, 2005). Eleven grids of 100 nest boxes each (modified from Sonenshine et al., 1973) were established with at least $3 \mathrm{~km}$ between grids and $40 \mathrm{~m}$ between adjacent boxes. Nest boxes were checked for pregnant females every 2 weeks during the breeding season (August-May). Pregnancy was assessed using the criteria of Sollberger (1943). Pregnant females were housed at the Savannah River Ecology Laboratory's animal care facility until the date of parturition. At parturition, litter size, offspring sex and offspring mass (to the nearest $0.1 \mathrm{~g}$ ) were recorded. Because females had usually been captured before, we consulted a dataset on this population to obtain measurements taken within 15 days of expected conception (backdated 40 days gestation from the parturition date). We used measurements for: head and body length (HB), head or skull length (SL), hindleg length (HF), foreleg length (FL) and body mass. All measurements were repeatable $\left(R^{2} \geq 0.80\right)$ as determined via analysis of variance. Comparisons of breeding experience were done using the mark-recapture history of females. Females previously observed with offspring or in breeding condition were labelled experienced breeders, whereas first-time breeders were those captured as juveniles in the previous season. Data on male body size were obtained from a randomly selected subset of a larger dataset compiled as part of a study on the reproductive biology of free-living flying squirrels (Risch, 1999). All live capture procedures followed ASM guidelines and were approved by the Institutional Animal Care and Use Committee at Auburn University, AL.

\section{Defining wing loading}

Wing loading (WL) is the ratio of body mass $(M)$ to the liftgenerating surface area $(A)$, and can be defined as

$$
\mathrm{WL}=\frac{M g}{A}
$$

where $g$ is the acceleration due to gravity. We calculated planar surface area of the patagium as a hypothetical trapezoidal shape with the mean length of the body (calculated from $\mathrm{HB}-\mathrm{SL}$ ), multiplied by the average of $4 \times \mathrm{HF}$ and $4 \times$ FL. Planar surface area is isometric with the appendicular and axial skeleton (Thorington \& Heaney, 1981), and although this method provides only an approximation, it is a reasonable index of the minimal airfoil area. To avoid statistical difficulties associated with the use of ratios (Packard \& Boardman, 1987), such as a ratio of body mass to airfoil area we used standardized residuals of a regression of body mass on planar surface area to assess wing loading, hereafter referred to as wing loading residuals. Thus, individuals with greater wing loading have larger residual values. However, we also analysed and present the 'traditional measure' of wing loading, as body mass versus airfoil area (Newtons of force per unit of airfoil area; $\mathrm{N} \mathrm{m}^{-2}$ ), assuming gravity remains constant during glided flight, to facilitate comparisons between sexes and reproductive states, using unpaired Wilcoxon's tests for male versus female comparisons.

\section{Statistical analysis}

To obtain wing loading residuals we used ordinary leastsquares (OLS) regression. Although, the use of OLS regression has been contested in situations where both the 
independent and dependent variables are subject to error, as a result of measurement (Harvey \& Pagel, 1991), a study by Schulte-Hostedde et al. (2005) has demonstrated that OLS regression satisfies critical assumptions about body size to a degree more favourable than other regression analyses. All linear measurement data were natural logarithm (ln) transformed to satisfy normality assumptions, as tested by Kolmogorov-Smirnov tests. Wing loading residuals were generated using a regression analysis including all individuals in a large dataset collected over several years $(n=1877)$. We were interested in examining how planar surface area varied with body mass, sex and female reproductive status. Residuals for pregnant and non-pregnant females were compared with those of males using two-sample $t$-tests. We also wanted to examine how planar surface area and body mass were associated within the three groups, this was done using analysis of covariance (ANCOVA) where planar surface area was the response variable and body mass and sex/status (group: males, pregnant females and non-pregnant females) were factors. To test differences in intercepts and slopes between groups, we included the interaction body mass $\times$ reproductive group in the model. Because the same females during both stages (pregnant and non-pregnant) were used, we adjusted the degrees of freedom in the ANCOVA model, by using the residual error of the model as the denominator in subsequent $F$-tests, to address potential concerns about independence of the data.

We determined mass while pregnant for each female by using the summed masses of individual offspring in a litter (litter mass) and adding this sum to each female's original body mass, providing us with a measure of female body mass during near-term pregnancy. We were interested in testing the relationship between wing loading, breeding experience and reproductive output (litter mass). However, body mass and more importantly body condition, are known to strongly influence reproduction in many species. Because both body condition and wing loading are influenced by body mass separating out their effects on reproduction can be statistically troublesome due to potential violation of independence assumptions. To attempt to separate the contributions of wing loading we used three methods. First, we used ANCOVA with litter mass as a response variable and female body mass, breeding experience and wing loading residuals (generated from OLS regression of all individuals) as factors. This enabled us separate the contribution of both wing loading and body mass to overall variation in reproductive output. The degrees of freedom were again adjusted to minimize effects of pseudoreplication. Second, we used litter mass residuals based on OLS regressions of litter mass on maternal (nonpregnant) body mass which provides a reproductive measure adjusted for the effects of body mass. Then we tested these litter mass residual values against the wing loading residual values and breeding experience. Lastly, we calculated the traditional measure of wing loading and it was related to the litter mass residuals, which were corrected for maternal body mass, and these were analysed separately for experienced and first-time breeding females. These approaches enable us to consider the influence of wing loading on reproduction independent of the affect that body mass or condition may impart. All statistics were performed using SPSS version $13.0^{\circledR}$ software and all values are reported as mean \pm standard error.

\section{Results}

\section{Reproduction in flying squirrels}

We measured 91 newborn litters from different females between 20 November 1994 and 25 March 1998: 66 springborn litters and 25 fall-born litters. We estimated wing loading for 91 adult males, randomly selected from a larger dataset. Using information from a mark-recapture study, known females breeding for the first-time accounted for 24 litters and 67 were from females with previous breeding experience. Mean litter size was $3 \pm 0.41$, with range from 1 to 5 . Mean neonate mass was $5.53 \pm 0.24 \mathrm{~g}$ and mean litter mass was $15.41 \pm 0.73 \mathrm{~g}$. Litter size was positively correlated with litter mass $(r=0.85, P<0.0001)$ and negatively correlated with mean neonatal mass $(r=-0.39, P=0.0009)$. Season did not influence litter size $\left(F_{1,89}=136.749\right.$, $P=0.897)$ or litter mass $\left(F_{1,89}=72.525, P=0.601\right)$.

\section{Sex and reproductive status effects on wing loading}

The results of the OLS regression of female body mass on airfoil area that was used to generate the wing loading residuals are presented in Table 1. Although analyses were done using regression residuals we depict a graphical representation of sex and reproductive status differences in airfoil area and body mass (Fig. 1). Both sex and reproductive status influenced wing loading (interaction term: groupmass; $F_{1,8}=7.46, P=0.016$ ). Wing loading in males was heavier than that for pregnant and non-pregnant females (comparison of intercepts; pregnant: $F_{1,90}=8.537$, $P=0.009$; non-pregnant: $F_{1,90}=6.151, P=0.021$; Fig. 1 ). The relationship between airfoil area and body mass differed significantly between males and non-pregnant females (comparison of slopes: $F_{1,90}=10.950, P=0.035$ ); however, the slope of the lines did not differ between males and

Table 1 Results of ordinary least squares (OLS) regression analyses of body mass on planar airfoil area for male and female southern flying squirrels Glaucomys volans at different reproductive stages

\begin{tabular}{lllll}
\hline & $n$ & $R^{2}$ & Slope (SE) & Intercept (SE) \\
\hline Complete model & 1877 & 0.683 & $0.97(0.24)$ & $47.28(9.23)$ \\
Sex and reproductive stages & & & & \\
$\quad$ Males & 91 & 0.781 & $5.72(0.29)$ & $39.22(4.28)$ \\
$\quad$ Non-pregnant females & 91 & 0.814 & $3.04(0.61)$ & $33.07(3.32)$ \\
$\quad$ Pregnant females & 91 & 0.790 & $5.60(0.57)$ & $18.75(2.08)$ \\
\hline
\end{tabular}

Complete model indicates analyses using all individuals in a large dataset. OLS regression parameters for sex and reproductive stage exclusive analyses also shown for comparison. All are significant with $P<0.05$. 


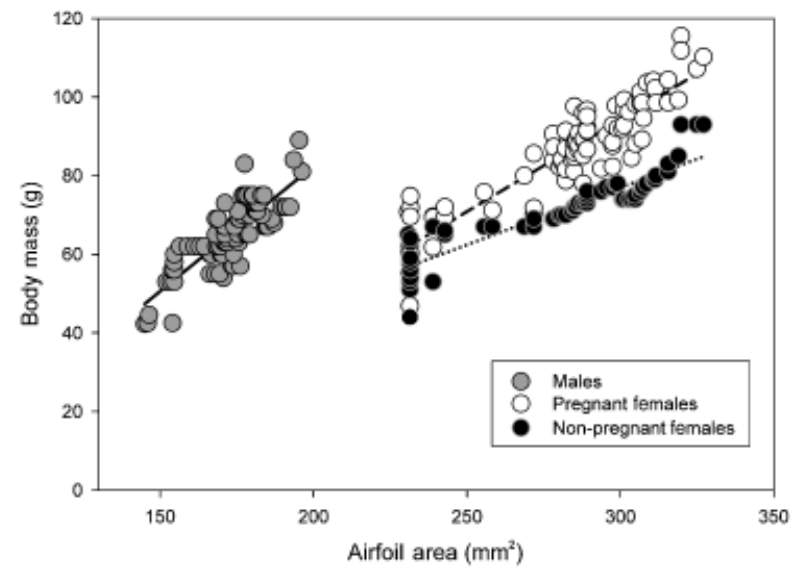

Figure 1 Relationships between body mass and airfoil area for male, pregnant female and non-pregnant female southern flying squirrels Glaucomys volans. Solid line (males, $n=91$ ), long dash line (pregnant females, $n=91$ ), and dotted line (non-pregnant females, $n=91$ ).

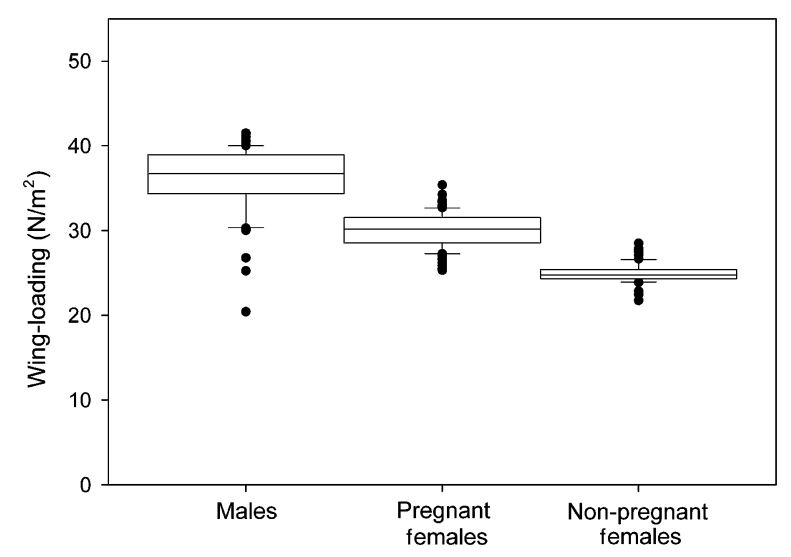

Figure 2 Comparisons of traditional 'wing loading' measurements, assuming constant gravity, for male, pregnant female and nonpregnant female southern flying squirrels Glaucomys volans. Box plots indicate median lines and the 25th and 75th percentiles and error bars indicate 10th and 90th percentiles. Filled circles indicate outlying data. All comparisons are statistically significant at $P<0.05$.

pregnant females (comparison of slopes: $F_{1,90}=0.383$, $P=0.322$ ). For non-pregnant females, the slope of the line of airfoil area on body mass was shallower, but became steeper when litter mass was added. A similar relationship was observed when comparing the traditional measure of wing loading $\left(\mathrm{N} \mathrm{m}^{-2}\right)$, with greater wing loading in males compared to both non-pregnant (Wilcoxon's test: $P=0.027$; Fig. 2) and pregnant females (Wilcoxon's test: $P=0.041$; Fig. 2).

\section{Wing loading, breeding experience and reproductive output}

We used ANCOVA to explore the relationships between maternal body mass, breeding experience and wing loading residuals on litter mass (Table 2). Breeding experience of the
Table 2 ANCOVA results and effect sizes for the influence of maternal body mass, breeding experience and wing loading on litter mass

\begin{tabular}{lclrl}
\hline Variable & $F$ & d.f. & $P$ & Partial $\varepsilon^{2}$ \\
\hline Model & 3.04 & 1,87 & 0.0053 & \\
Comparisons of intercepts & 9.21 & 1,1 & $\leq 0.0001$ & 0.112 \\
Breeding experience & 0.628 & 1,1 & 0.2864 & 0.07 \\
Wing loading residuals & 17.17 & 1,41 & $\leq 0.0001$ & 0.181 \\
Maternal body mass & 33.48 & 1,41 & $\leq 0.0001$ & 0.762 \\
\hline
\end{tabular}

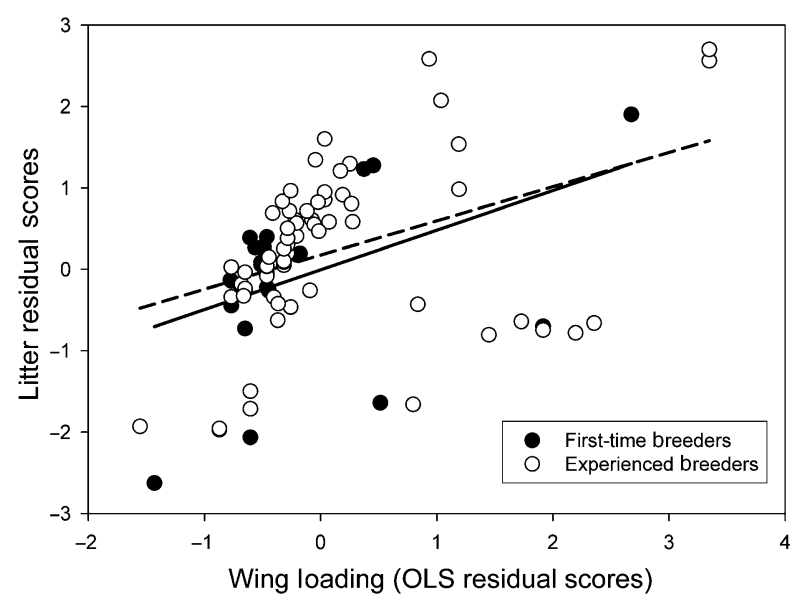

Figure 3 Relationship between female wing loading, breeding experience and litter mass in the southern flying squirrel Glaucomys volans. Both wing loading and litter mass are expressed as the residuals of an ordinary least squares regression. Solid line indicates first-time breeders (primiparous, $n=24$ ) and dashed line indicates experienced females $(n=67)$.

mother was not associated with litter mass. However, both maternal body mass and wing loading were associated with litter mass (Table 2). Females with greater wing loading than predicted by their body size $\left(R^{2}=0.421, F_{1,90}=2.92\right.$, $P=0.023)$ generally bore heavier litters regardless of breeding experience (Table 2). We also investigated the relationship between maternal wing loading and reproduction by controlling for maternal body mass effects on litter mass using litter mass residuals (Table 2). Females with greater wing loading beyond that expected for their body size bore heavier litters $\left(F_{1,90}=14.002, P \leq 0.001\right.$; Fig. 3$)$, but litter mass did not differ between 24 first-time and 67 experienced breeders (comparison of slopes: $F_{1,89}=0.62, P=0.311$; comparison of intercepts: $F_{1,89}=0.9 .342, P=0.235$; Fig. 3). Using the traditional measure of wing loading, as $\mathrm{Nm}^{-2}$, females with greater wing loading bore larger litters $\left(R^{2}=0.329, \quad F_{1,89}=4.31, \quad P=0.025\right)$, but females with breeding experience did not differ in wing loading from first time breeders (Wilcoxon's test: $P=0.414$; Fig. 4).

\section{Discussion}

To investigate the hypothesis that increased wing loading during pregnancy imposes constraints on reproduction we 


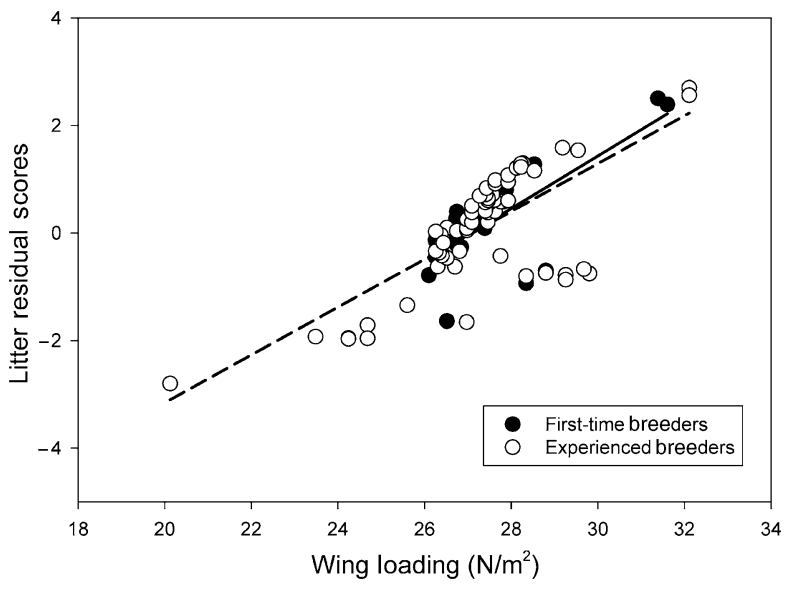

Figure 4 Relationship between female wing loading (as $\mathrm{Nm}^{-2}$ ), breeding experience and litter mass (expressed as residuals of an ordinary least squares regression) in the southern flying squirrel Glaucomys volans. Solid line indicates first-time breeders (primiparous, $n=24)$ and dashed line indicates experienced females $(n=67)$.

tested three predictions concerning intersexual variation in wing loading and its relationship to reproductive output in southern flying squirrels. Although males on average weighed less than females, they had greater wing loadings than either pregnant or non-pregnant females. However, the association of body mass and airfoil area was similar between males and pregnant females. Heavier females gave birth to heavier litters, and females with greater wing loading, than would be expected from their body mass, also bore heavier litters. This result does not support the wing loading hypothesis, which predicted an opposite relationship.

\section{Intersexual variation in wing loading}

Intersexual differences in wing loading were most apparent when comparing males to non-pregnant females. Comparisons of males to females when litter mass was added (i.e. pregnant females) resulted in similar regression slopes. This suggests that larger structural size in females may easily accommodate the added mass during pregnancy without having a negative effect on gliding locomotion. Such an association was also reported by Robins et al. (2000) for G. volans. Flight imposes unique and strict constraints on structural morphology, and minimizing wing loading is a central tenet behind many of the adaptations to both gliding and flight. For instance, to minimize wing loading, bats have reduced the size of the anterior and posterior regions of the body, so that the centre of mass is pectoral (Myers, 1978). Heavier bat species have proportionally longer wings (Myers, 1978; Hayssen \& Kunz, 1996) and in species exhibiting female-biased SSD, females also have proportional longer wings than males (Hayssen \& Kunz, 1996). Intersexual differences in planar surface area resulting from sex-specific factors designed to optimize aerial locomotion have also been proposed for some bird species, such as wandering albatross Diomedea exulans (Shaffer, Weimers- kirch \& Costa, 2001), some shorebirds (Jehl \& Murray, 1986) and raptors (Andersson \& Norberg, 1981). Another line of evidence for intersexual differences related to gliding is provided by female-biased sexual dimorphism in gliding species of Draco, which differs from the predominant malebiased dimorphism seen in other agamid lizards (Shine et al., 1998).

\section{Gliding and reproduction: a trade-off?}

Maternal investment in reproduction is influenced by a myriad of ecological and physiological factors including body condition (Festa-Bianchet, 1998; Dobson, Risch \& Murie, 1999; King \& Allaine, 2002), predation risk (Fontaine \& Martin, 2006), bet-hedging or restraint strategies (James \& Whitford, 1994; Broussard et al., 2003), direct assessment of future reproductive opportunities (Hanssen, 2006) and breeding experience (Fokidis et al., 2007). In our study, female $G$. volans with greater wing loading produced heavier litters, and this pattern persisted using three methods to account for the effects of maternal body mass. This contradicts our a priori prediction that females with lower wing loading would have larger litters because they could accommodate increased mass.

One interpretation is that increased wing loading during pregnancy may not constrain reproduction directly, but indirectly. For example, increased wing loading may influence reproduction, by affecting how efficiently a female can gather food resources, and maintain high energetic stores. Females with increased wing loading (increased body mass relative to structural size) could have greater energy reserves that could increase capacity for reproduction. In many species, measures of body condition correlate with reproductive output (Festa-Bianchet, 1998; Dobson et al., 1999; King \& Allaine, 2002) and studies manipulating nutritional availability demonstrate correlated responses in reproduction (Ylonen \& Eccard, 2004). In sciurids, annual changes in female mass correlate with annual changes in litter size (Risch, Dobson \& Murie, 1995; Risch, Michener \& Dobson, 2007). Conceivably a trade-off may exist between maintaining gliding ability and having to increase energy reserves in preparation for reproduction in gliding animals, such as $G$. volans. Thus maximizing fecundity may compromise gliding efficiency.

An alternate explanation concerns our derivation of wing loading based on the assumption of a static trapezoidal planar gliding surface and positive allometry of the fore and hind limbs. Although this method is useful, it is only an index of the 'minimal area' of the airfoil available to an individual to obtain lift. Studies of the kinematics of gliding transport have demonstrated that gliding is far from a passive process, and depending on the stages of a glide, environmental conditions or behaviour of the glider, the airfoil area can change in shape and size (Addington, Scheibe \& Hendershott, 2000; Jackson, 2000; Keith, Scheibe \& Hendershott, 2000; Bishop, 2004, 2006). Thus, our measure of wing loading does not accommodate these other factors, which may strongly influence gliding performance. 


\section{Wing loading and other factors in the evolution of female-biased SSD}

Studies of other volant taxa have cited natural or sexual selection on wing loading as a major driving force in the evolution of female-biased SSD (Myers, 1978; Jehl \& Murray, 1986; Shine et al., 1998; Shaffer et al., 2001). Although, we tested a possible mechanism of selection acting on female fecundity through wing loading constraints, patterns of SSD represent selection acting on both sexes. In considering intersexual differences in wing loading and body size one must also consider why males are smaller. Selection may be acting on male body size to increase mobility during the 'mate chase' characteristic of arboreal sciurids (Koprowski, 1993). Schulte-Hostedde \& Millar $(2002 a, b)$ in a study of yellow-pine chipmunks Tamias amoenus hypothesized that body size in males influenced mating tactics, with larger individuals attaining greater running speeds, but smaller males being more aggressive. Both tactics might be effective at gaining mating opportunities during male-male competition for females. In $G$. volans, which exhibits a similar mating system to T. amoenus, smaller males (i.e. those with lower wing loading) may be more effective gliders which may in turn result in greater mating success.

Additionally, larger body size may provide other benefits exclusive of wing loading and gliding performance for female G. volans. Larger females may be capable of defending larger territories or those with increased food resources and thus exhibit higher fecundity. In our population, larger females have home ranges that contain a greater proportion of mast-producing trees, which are a major food resource during the breeding season (Fokidis et al., 2007). This increased resource availability within a home range may translate to increased fecundity, as documented in the Eurasian red squirrel Sciurus vulgaris (Wauters \& Dhondt, 1995). Another important resource to G. volans are snags and tree cavities and these may be more easily exploited by larger individuals as suggested by larger female G. volans having a larger proportion of cavity producing hardwood trees in their home range (Fokidis et al., 2007). Female $G$. volans often maintain three or more nesting sites, and transfer offspring between them during the rearing period (Dolan \& Carter, 1977). Thus access to multiple cavities may be an important resource. However, a study in which tree cavity availability was manipulated failed to demonstrate a change in population densities of $G$. volans, suggesting that cavity availability may not be a limiting resource in our study population (Brady et al., 2000).

\section{Conclusion}

Our study provides some support that intersexual differences in wing loading, and specifically the larger structural size of females, may result from the need to minimize the effect of pregnancy on gliding ability. However, the degree to which the burden of gliding while pregnant influences reproduction is unclear, largely due to the difficulty of statistically separating the effects of wing loading from those of body mass, which is known to influence reproduction in many taxa. Species exhibiting specialized locomotory modes could provide useful models for assessing the costs of reproduction and provide much needed insight concerning the evolution of life-history patterns.

\section{Acknowledgements}

Special thanks to both Matthew Brady for assistance with fieldwork and Christy Robertson for help with data entry. We thank Ken Norris, Virginia Hayssen and F. Stephen Dobson for insightful comments on the paper. This study was funded by contract DE-FC09-96SR18546 between the US Department of Energy and the Savannah River Ecology Laboratory. T.S.R. was further supported by National Science Foundation grant DEB-9521013, a National Environmental Research Park grant, and grants in aid from the American Society of Mammalogists, American Museum of Natural History, Sigma Xi, and the ASM Shadle Fellowship. Additional funds were provided by the American Museum of Natural History to H.B.F. Paper preparation was supported in part by a reassignment time grant to T.S.R. from the Environmental Sciences Program at Arkansas State University.

\section{References}

Addington, T.M., Scheibe, J.S. \& Hendershott, A.J. (2000). Planar surface area and launch performance in Glaucomys volans. In Biology of gliding mammals: 199-211. Goldingay, R. \& Scheibe, J.S. (Eds). Furth, Germany: Filander Press.

Andersson, M. (1994). Sexual selection. New Jersey: Princeton University Press.

Andersson, M. \& Norberg, R.A. (1981). Evolution of reversed sexual size dimorphism and role partitioning among predatory birds with a size scaling of flight performance. Biol. J. Linn. Soc. 15, 105-130.

Bishop, K.L. (2004). Kinematics of short glides in the southern flying squirrel, Glaucomys volans. Integr. Comp. Biol. 44, 525-525.

Bishop, K.L. (2006). The relationship between 3-D kinematics and gliding performance in the southern flying squirrel, Glaucomys volans. J. Exp. Biol. 209, 689-701.

Blackburn, D.G. \& Evans, H.E. (1986). Why are there no viviparous birds? Am. Nat. 128, 165-190.

Brady, M.J., Risch, T.S. \& Dobson, F.S. (2000). Availability of nest sites does not limit population size of southern flying squirrels. Can. J. Zool. 78, 144-1149.

Broussard, D.R., Risch, T.S., Dobson, F.S. \& Murie, J.O. (2003). Senescence and age-related reproduction of female Columbian ground squirrels. J. Anim. Ecol. 72, 212-219.

Darwin, C.R. (1874). The descent of man, and selection in relation to sex, 2nd edn. New York: Appleton Press.

Davenport, J. (2003). Allometric constraints on stability and maximum size in flying fish: implications for their evolution. J. Fish Biol. 62, 455-463. 
Dobson, F.S., Risch, T.S. \& Murie, J.O. (1999). Increasing returns in the life history of Columbian ground squirrels. J. Anim. Ecol. 68, 73-86.

Dolan, P.G. \& Carter, D.C. (1977). Glaucomys volans. Mamm. Species 78, 1-6.

Festa-Bianchet, M. (1998). Condition-dependent reproductive success in bighorn ewes. Ecol. Lett. 2, 91-94.

Fokidis, H.B. (2004). The effects of female age on sexual size dimorphism and multiple paternity in the southern flying squirrel. MSc thesis, Arkansas State University, Jonesboro, AR, USA.

Fokidis, H.B. \& Risch, T.S. (2005). The use of nest boxes to sample arboreal vertebrates. Southeast. Nat. $\mathbf{4}$, 447-458.

Fokidis, H.B. \& Risch, T.S. (2008). The burden of motherhood: gliding locomotion in mammals influences maternal reproductive investment. J. Mammal., 89.

Fokidis, H.B., Risch, T.S. \& Glenn, T.C. (2007). Reproductive and resource benefits to large female body size in a mammal exhibiting female-biased sexual size dimorphism. Anim. Behav. 73, 479-488.

Fontaine, J.J. \& Martin, T.E. (2006). Parent birds assess nest predation risk and adjust their reproductive strategies. Ecol. Lett. 9, 428-434.

Guillemette, M. \& Ouellet, J.F. (2005). Temporary flightlessness as a potential cost of reproduction in pre-laying common eiders Somateria mollissima. Ibis 147, 301-306.

Hanssen, S.A. (2006). Costs of an immune challenge and terminal investment in a long-lived bird. Ecology 87, 2440-2446.

Harvey, P.H. \& Pagel, M.D. (1991). The comparative method in evolutionary biology. Oxford: Oxford University Press.

Hayssen, V. \& Kunz, T.H. (1996). Allometry of litter mass in bats: maternal size, wing morphology, and phylogeny. J. Mammal. 77, 476-490.

Holmes, D.J. \& Austad, S.N. (1994). Fly now, die later: life history correlates of gliding and flying in mammals.

J. Mammal. 75, 224-226.

Howard, R.D., Martens, R.S., Innis, S.A., Drnevich, J.M. \& Hale, J. (1998). Mate choice and mate competition influence male body size in Japanese Medaka. Anim. Behav. 55, 1151-1163.

Jackson, S.M. (2000). Glide angle in the genus Petaurus and a review of gliding in mammals. Mammal Rev. 30, 9-30.

James, C.D. \& Whitford, W.G. (1994). An experimentalstudy of phenotypic plasticity in the clutch size of a lizard. Oikos 70, 49-56.

Jehl, J.R. \& Murray, B.G. Jr. (1986). The evolution of normal and reverse sexual size dimorphism in shorebirds and other birds. Curr. Ornithol. 3, 1-86.

Karubian, J. \& Swaddle, J.P. (2001). Selection on females can lead to 'larger males'. Proc. Roy. Soc. Lond. Ser. B 268, 725-728.

Keith, M.M., Scheibe, J.S. \& Hendershott, A.J. (2000). Launch dynamics in Glaucomys Volans. In Biology of gliding mammals: 185-198. Goldingay, R. \& Scheibe, J.S. (Eds). Furth, Germany: Filander Press.

King, W.J. \& Allaine, D. (2002). Social, maternal, and environmental influences on reproductive success in female Alpine marmots (Marmota marmota). Can. J. Zool. 12, 2137-2143.

Koprowski, J.L. (1993). Alternative reproductive tactics in male eastern gray squirrels: "making the best of a bad job". Behav. Ecol. 4, 165-171.

Kruuk, H. (1972). The spotted Hyaena: a study of predation and social behaviour. Chicago: University of Chicago Press.

Lee, P.F. (1998). Body size comparison of two giant flying squirrel species in Taiwan. Acta Zool. Taiwanica 9, 51-57.

Lee, P.F., Lin, Y.S. \& Progulske, D.R. (1993). Reproductive biology of the red-giant flying squirrel, Petaurista petaurista, in Taiwan. J. Mammal. 74, 982-989.

Loison, A., Gaillard, J.M., Pelabon, C. \& Yoccoz, N.G. (1999). What factors shape sexual size dimorphism in ungulates? Evol. Ecol. Res. 1, 611-633.

Madden, J.R. (1974). Female territoriality in a Suffolk County, Long Island, population of Glaucomys volans. J. Mammal. 55, 647-652.

Mcguire, J.A. \& Dudley, R. (2005). The cost of living large: comparative gliding performance in flying lizards (Agamidae: Draco). Am. Nat. 166, 93-106.

Mueller, H.C. \& Meyer, K. (1985). Evolution of reversed sexual dimorphism in Falconiforms. Curr. Ornithol. 2, 65-101.

Myers, P. (1978). Sexual dimorphism in size of vespertilionid bats. Am. Nat. 112, 701-711.

Olsson, M., Shine, R. \& Bak-Olsson, E. (2000). Locomotor impairment of gravid lizards: is the burden physical or physiological? J. Evol. Biol. 13, 263-268.

Packard, G.C. \& Boardman, T.J. (1987). The misuse of ratios to scale physiological data that vary allometrically with body size. In Directions in ecological physiology: 216-238. Feder, M.E., Bennett, A.F., Burggren, W.W. \& Huey, R.B. (Eds). Cambridge, UK: Cambridge University Press.

Ralls, K. (1976). Mammals in which females are larger than males. Quart. Rev. Biol. 51, 245-276.

Reeve, J.P. \& Fairburn, D.J. (1999). Change in sexual size dimorphism as a correlated response to selection on fecundity. Heredity 83, 697-706.

Risch, T.S. (1999). Significance of litter size and costs of reproduction in small mammals. $\mathrm{PhD}$ thesis. Auburn University, Auburn, AL, USA.

Risch, T.S., Dobson, F.S. \& Murie, J.O. (1995). Is mean litter size the most productive? A test in Columbian ground squirrels. Ecology 76, 1643-1654.

Risch, T.S., Michener, G.R. \& Dobson, F.S. (2007). Variation in litter size: a test of hypotheses in Richardson's ground squirrels. Ecology 88, 306-314.

Robins, J.H., Scheibe, J.S. \& Laves, K. (2000). Sexual size dimorphism and allometry in southern flying squirrels, Glaucomys volans. In Biology of gliding mammals: 229-248. 
Goldingay, R. \& Scheibe, J.S. (Eds). Furth, Germany: Filander Press.

Schulte-Hostedde, A.I. \& Millar, J.S. (2002a). 'Little chipmunk' syndrome? Male body size and dominance in captive yellowpine chipmunk (Tamias amoenus). Ethology 108, 127-137.

Schulte-Hostedde, A.I. \& Millar, J.S. (2002b). Effects of body size and mass on running speed of male yellowpine chipmunks (Tamias amoenus). Can. J. Zool. 80, 1584-1587.

Schulte-Hostedde, A.I., Millar, J.S. \& Gibbs, H.L. (2002). Female-biased sexual size dimorphism in the yellow-pine chipmunk (Tamias amoenus): sex-specific patterns of annual reproductive success and survival. Evolution 56, 2519-2529.

Schulte-Hostedde, A.I., Millar, J.S. \& Gibbs, H.L. (2004). Sexual selection and mating patterns in a mammal with female-biased sexual size dimorphism. Behav. Ecol. 15, 351-356.

Schulte-Hostedde, A.I., Zinner, B., Millar, J.S. \& Hickling, G.J. (2005). Restitution of mass-size residuals: validating body condition indices. Ecology 86, 155-163.

Shaffer, S.A., Weimerskirch, H. \& Costa, D.P. (2001). Functional significance of sexual dimorphism in wandering albatrosses, Diomedea exulans. Funct. Ecol. 15, 203-210.

Shine, R. (1988). Constraints on reproductive investment: a comparison between aquatic and terrestrial snakes. Evolution 42, 17-27.

Shine, R. (1989). Ecological causes for the evolution of sexual dimorphism: a review of the evidence. Quart. Rev. Biol. 64, 419-461.

Shine, R. (2003). Effects of pregnancy on locomotor performance: an experimental study on lizards. Oecologia 136, 450-456.
Shine, R., Keogh, S., Doughty, P. \& Giragossyan, H. (1998). Costs of reproduction and the evolution of sexual dimorphism in a 'flying lizard' Draco melanopogon (Agamidae). J. Zool. (Lond.) 246, 203-213.

Slatkin, M. (1984). Ecological causes of sexual dimorphism. Evolution 38, 622-630.

Sollberger, D.E. (1943). Notes on the breeding habits of the eastern flying squirrel (Glaucomys volans volans). J. Mammal. 24, 163-173.

Sonenshine, D.E., Cerretani, D.G, Enlow, G. \& Elisberg, B.L. (1973). Improved methods for capturing wild flying squirrels. J. Wildl. Mgmt. 37, 588-590.

Stapp, P. (1992). Energetic influences on the life history of Glaucomys volans. J. Mammal. 73, 914-920.

Temeles, E.J., Pan, I.L., Brennan, J.L. \& Horwitt, J.N. (2000). Evidence for ecological causation of sexual dimorphism in a hummingbird. Science 289, 441-443.

Thorington, R.W. \& Heaney, L.R. (1981). Body proportions and gliding adaptations of flying squirrels (Petauristinae). J. Mammal. 62, 101-114.

Wauters, L.A. \& Dhondt, A.A. (1995). Lifetime reproductive success and its correlates in female Eurasian red squirrels. Oikos 72, 402-410.

Webster, M.S. (1997). Extreme sexual size dimorphism, sexual selection, and the foraging ecology of Montezuma Oropendolas. Auk 114, 570-580.

Ylonen, H. \& Eccard, J.A. (2004). Does quality of winter food affect spring condition and breeding in female bank voles (Clethrionomys glareolus)? Ecoscience 11, 1-5.

Yoccoz, N.G. \& Mesnager, S. (1998). Are alpine bank voles larger and more sexually dimorphic because adults survive better? Oikos 82, 85-98. 